\title{
Endoscopic ultrasound-guided gastroenterostomy using a metal stent for the treatment of afferent loop syndrome
}
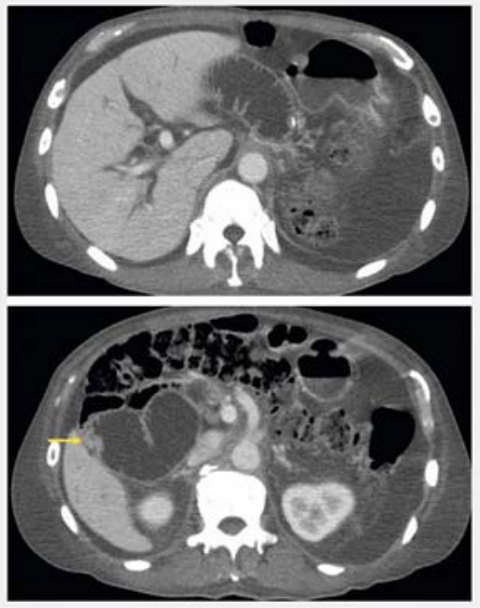

- Fig. 1 Computed tomography scan showing intestinal and bile duct dilation. At the onset of afferent loop syndrome, disseminated nodules (arrow) were observed.

A 79-year-old man with a history of pylorus-preserving pancreaticoduodenectomy for pancreatic head cancer and Child's reconstruction underwent total pancreatectomy for remnant pancreatic recurrence 2 years later. Four months after total pancreatectomy, he developed cholangitis. Computed tomography (CT) (> Fig.1) showed afferent loop syndrome arising from disseminated peritoneal nodule formation. We attempted to place an intestinal stent at the afferent loop stenosis site to resolve the obstructive jaundice and cholangitis.

Although the endoscope (CF-H260Al; Olympus Medical Systems, Tokyo, Japan) reached the stenotic region, advancing the guidewire was difficult and placing the stent was impossible because it was difficult to visualize the stenosis squarely ( Fig.2). Thus, the procedure was converted to endoscopic ultrasound (EUS)guided fistulization from the remnant stomach to the afferent loop ( $\vee$ Video 1$)$.
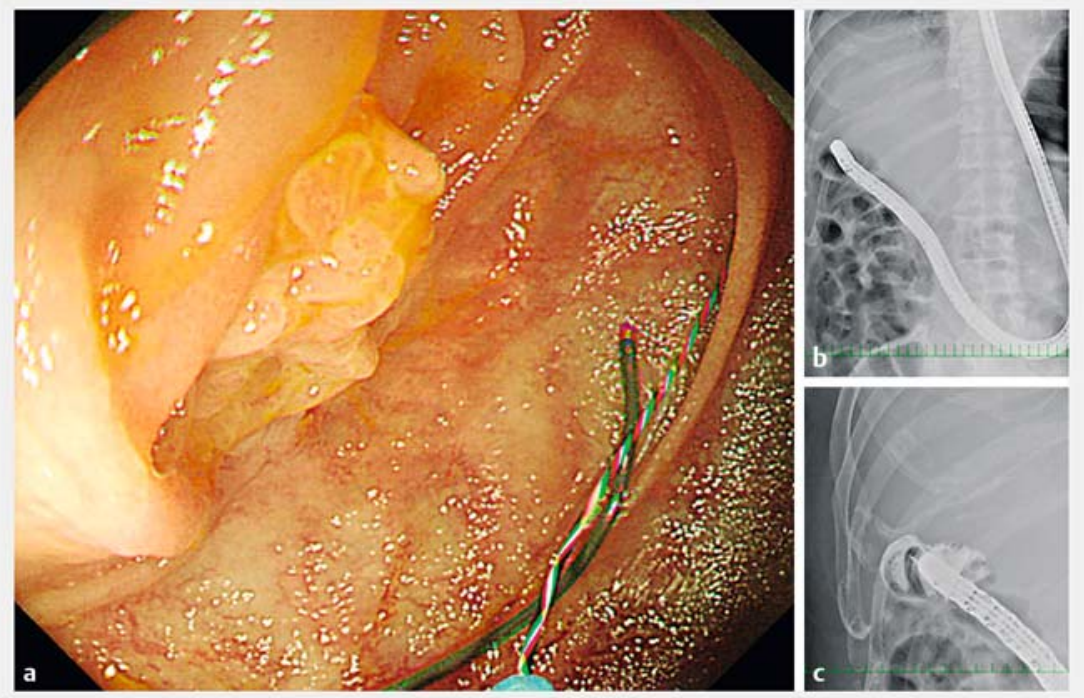

- Fig. 2 The intestinal bend and severe stenosis obstructed the guidewire. a Endoscopic image of the intestinal bend. b, $\mathbf{c}$ Fluoroscopic images showing severe stenosis.
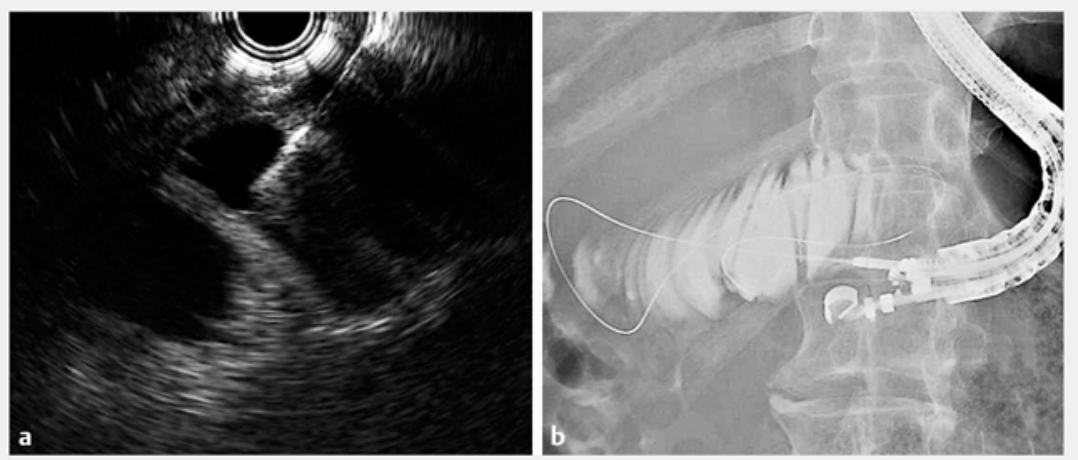

- Fig. 3 Endoscopic ultrasound (EUS)-guided transgastric afferent loop drainage. a Puncture of the dilated intestinal tract under EUS guidance using a 19-gauge needle. $\mathbf{b}$ The guidewire was placed in the afferent loop.

The afferent loop extending from the remnant stomach was confirmed by EUS, followed by puncture with a 19-gauge needle (EZ Shot 3 Plus; Olympus Medical Systems, Tokyo, Japan) ( $\mathbf{F i g . 3 a ) . ~ A f t e r ~}$ using contrast imaging to confirm that the needle had penetrated the intestinal tract, a 0.025-inch guidewire (VisiGlide
2; Olympus Medical Systems) was advanced into the dilated intestinal tract ( $\triangleright$ Fig.3b). Blunt dilation using an ES Dilator (Zeon Medical, Tokyo, Japan) was attempted, but it was difficult; thus, the fistula was dilated using a diathermic dilator (Cysto-Gastro-Set; Endo-Flex GmbH, Voerde, Germany), followed by place- 

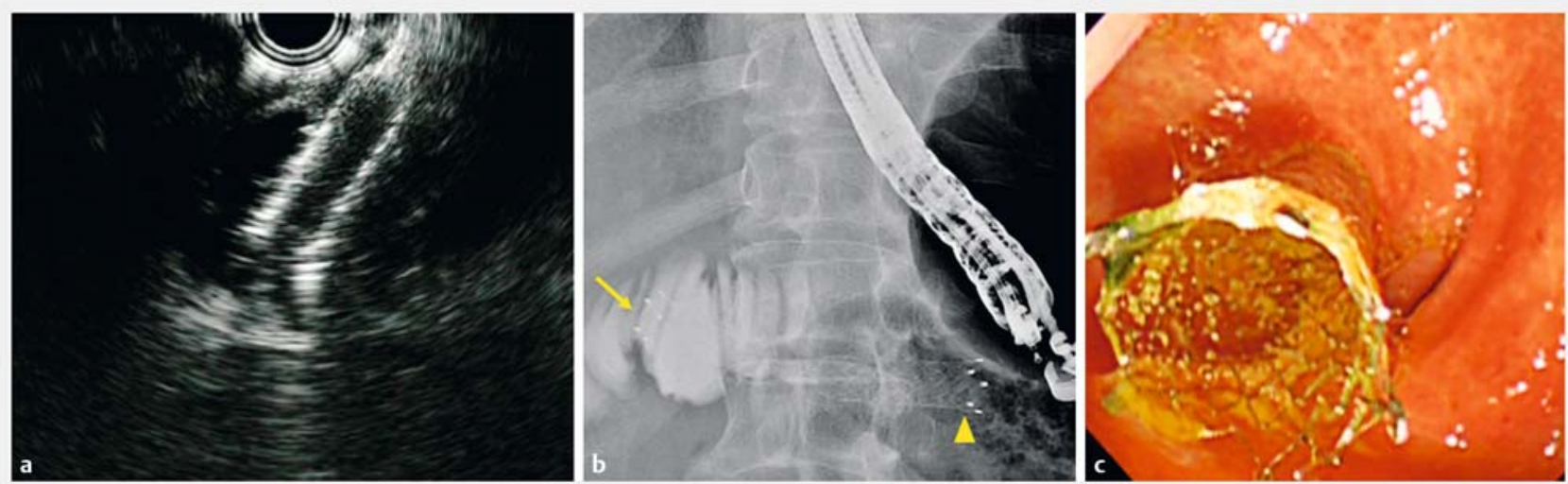

- Fig.4 An X-Suit NIR fully covered metal stent (Olympus Medical Systems, Tokyo, Japan) was placed between the remnant stomach and afferent loop. a Endoscopic ultrasound image taken during deployment of the stent into the afferent loop. $\mathbf{b}$ Fluoroscopic image showing the stent (arrow, distal end of the stent; arrowhead, proximal end of the stent). c Endoscopic image taken inside the remnant stomach immediately after stent placement.
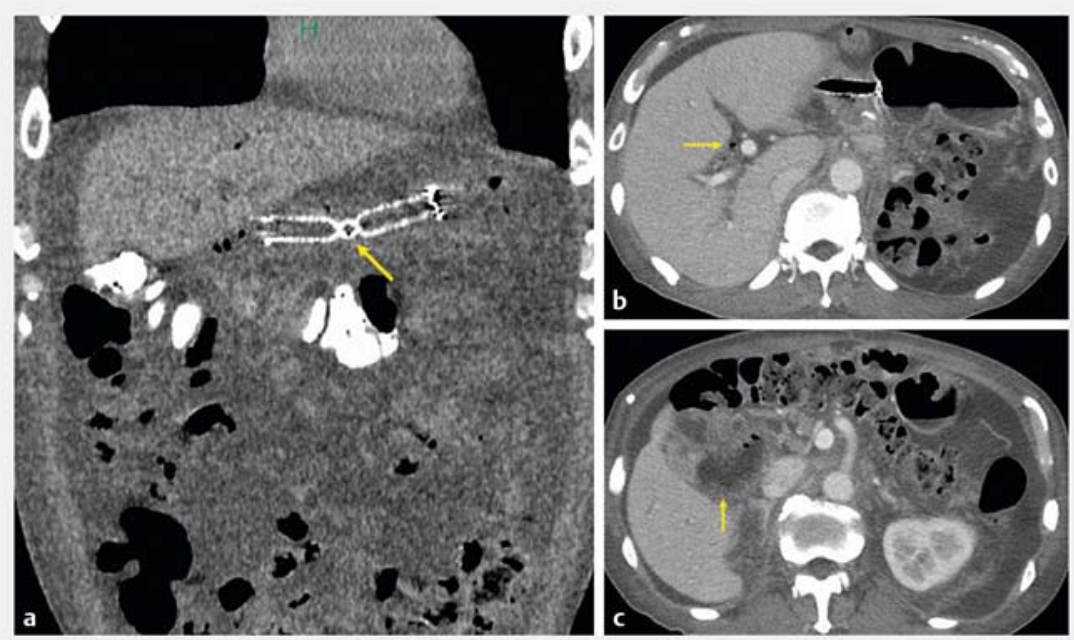

- Fig. 5 Computed tomography (CT) image after afferent loop drainage. a Coronal CT showing full view of the metal stent with notch (arrow). b Pneumobilia (arrow) appeared. c The dilation of the afferent loop improved (arrow).
The authors

Yasunari Sakamoto' ${ }^{1}$, Susumu Hijioka ${ }^{1}$, Yuta Maruki ${ }^{1}$, Akihiro Ohba', Yoshikuni Nagashio', Takuji Okusaka ${ }^{1}$, Yutaka Saito ${ }^{2}$

1 Department of Hepatobiliary and Pancreatic Oncology, National Cancer Center Hospital, Tokyo, Japan

2 Endoscopy Division, National Cancer Center Hospital, Tokyo, Japan

Corresponding author

\section{Susumu Hijioka, MD}

Department of Hepatobiliary and Pancreatic Oncology, National Cancer Center Hospital, 5-1-1 Tsukiji, Chuo-ku, Tokyo, Japan Fax: +81-3-35423815

shijioka@ncc.go.jp ment of a fully covered metal stent (X-Suit NIR $10 \mathrm{~mm} 8 \mathrm{~cm}$; Olympus Medical Systems) (\Fig.4). No complications were observed, and the patient's liver dysfunction and cholangitis promptly improved ( Fig.5).

Although previous reports have described the use of plastic stents [1-3] and lumen-apposing metal stents [3-5], this is the first report on the use of a tubular type metal stent. This method is effective in treating afferent loop syndrome if placement of an endoscopic intestinal stent is difficult.

Endoscopy_UCTN_Code_TTT_1AP_2AD

\section{Competing interests}

None 


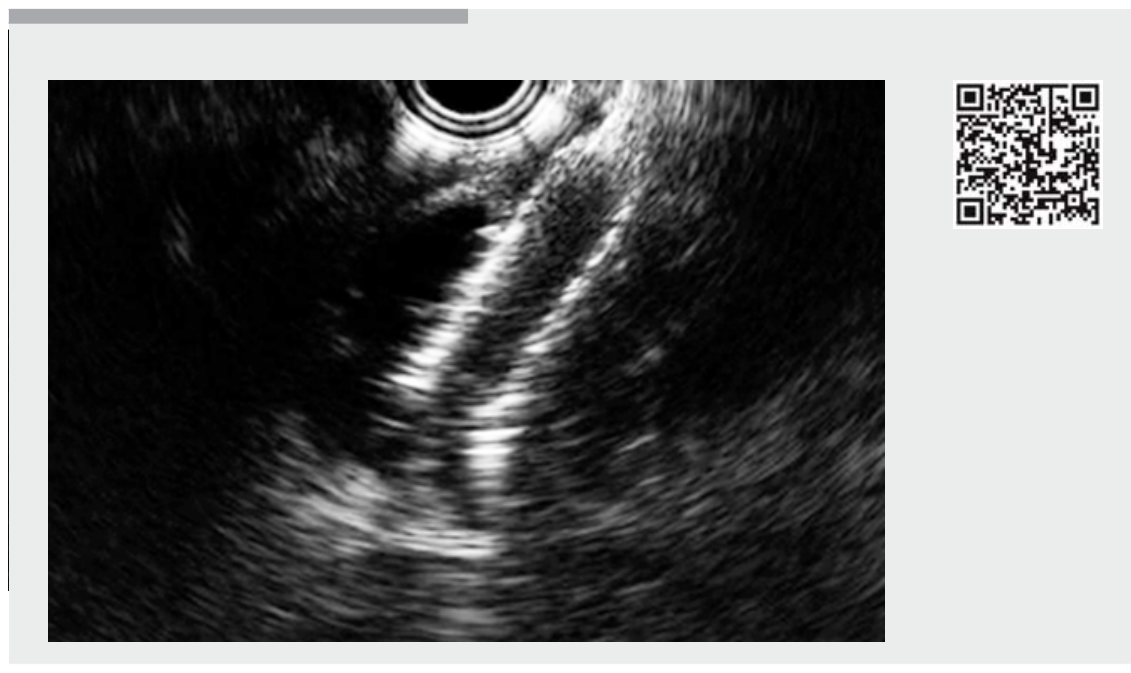

Video 1 It was difficult to place the stent for stenosis in the afferent loop. We could place the endoscopic ultrasound-guided gastroenterostomy using a metal stent.

\section{References}

[1] Matsumoto $\mathrm{K}$, Kato $\mathrm{H}$, Tomoda T et al. A case of acute afferent loop syndrome treated by transgastric drainage with EUS. Gastrointest Endosc 2013; 77: 132-133

[2] Bamba S, Shiomi H, Fujiyama Y. Afferent loop syndrome successfully treated by endoscopic ultrasound-guided transgastric drainage. Dig Endosc 2013; 25: 632-623

[3] Yamamoto K, Tsuchiya T, Tanaka R et al. Afferent loop syndrome treated by endoscopic ultrasound-guided gastrojejunos- tomy, using a lumen-apposing metal stent with an electrocautery-enhanced delivery system. Endoscopy 2017; 49: E270 - E272

[4] Ikeuchi N, Itoi T, Tsuchiya T et al. One-step EUS-guided gastrojejunostomy with use of a lumen-apposing metal stent for afferent loop syndrome treatment. Gastrointest Endosc 2015; 82: 166

[5] Brewer Gutierrez OI, Irani SS, Ngamruengphong $S$ et al. Endoscopic ultrasound-guided entero-enterostomy for the treatment of afferent loop syndrome: a multicenter experience. Endoscopy 2018; 50: 891 - 895

\section{Bibliography}

DOI https://doi.org/10.1055/a-0861-9821

Published online: 1.4.2019

Endoscopy 2019; 51: E153-E155

(c) Georg Thieme Verlag KG

Stuttgart · New York

ISSN 0013-726X

\section{ENDOSCOPY E-VIDEOS}

https://eref.thieme.de/e-videos

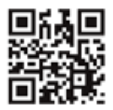

Endoscopy E-Videos is a free access online section, reporting on interesting cases and new techniques in gastroenterological endoscopy. All papers include a high quality video and all contributions are freely accessible online.

This section has its own submission website at

https://mc.manuscriptcentral.com/e-videos 